\title{
$\beta$-blocker use before elective percutaneous coronary intervention as a risk factor for periprocedural myocardial injury incidence in male patients below 75 years old: a single-center retrospective study
}

\author{
Min Wang", Qingbo Lv", Yao Wang, Yongchen Wang, Maoning Lin, Liding Zhao, Guosheng Fu, \\ Wenbin Zhang
}

Key Laboratory of Cardiovascular Intervention and Regenerative Medicine of Zhejiang Province, Department of Cardiology, Sir Run Run Shaw Hospital, School of Medicine, Zhejiang University, Hangzhou, China

Contributions: (I) Conception and design: G Fu, W Zhang; (II) Administrative support: None; (III) Provision of study materials or patients: None; (IV) Collection and assembly of data: M Wang, Q Lv; (V) Data analysis and interpretation: Y Wang, L Zhao; (VI) Manuscript writing: All authors; (VII) Final approval of manuscript: All authors.

\#These authors contributed equally to this work.

Correspondence to: Guosheng Fu, MD, PhD; Wenbin Zhang, MD, PhD. Key Laboratory of Cardiovascular Intervention and Regenerative Medicine of Zhejiang, Department of Cardiology, Sir Run Run Shaw Hospital, School of Medicine Zhejiang University, 3 East Qingchun Road, Hangzhou, China. Email: fugs@zju.edu.cn; 3313011@zju.edu.cn.

Backgroundz $\beta$-blockers are indicated in several cardiovascular diseases. However, data are limited on their
effect on the periprocedural myocardial injury (PMI) incidence. This study was designed to evaluate the
impact of using $\beta$-blockers before elective percutaneous coronary intervention (PCI) on PMI incidence.
Methods: This study included 4,027 patients who underwent elective PCI and had no elevated serum
troponin I (TnI) or creatine kinase-MB (CK-MB) levels before PCI. Patients were divided into four groups
based on gender and age (cut-off point 75 years). Serum TnI and CK-MB levels were measured before and
every eight hours after the procedure. PMI was defined as postprocedural TnI or CK-MB $\geq 5$ times the upper
limits of normal (ULN) values. Logistic regression analysis including factors such as age, sex, prior $\beta$-blocker
therapy, previous MI, length of implanted stents, characteristics of lesion and so on was performed to assess
the effects of prior $\beta$-blocker therapy on the incidence of PMI.
Results: In 2,332 male patients $<75$ years old, PMI incidence was higher in the $\beta$-blocker pre-usage
subgroup than the no $\beta$-blocker pre-usage subgroup ( $16.4 \%$ vs. $11.7 \%$, respectively; P=0.001). For the female
patients $\geq 75$ years old, the $\beta$-blocker pre-usage subgroup had a lower PMI incidence compared with the no
$\beta$-blocker pre-usage subgroup ( $18.2 \%$ s. $31.7 \%$, respectively; P=0.012). In logistic regression analysis, the
total length of implanted stents was a risk factor for PMI incidence in all patients. Also, $\beta$-blocker pre-usage
was an independent risk factor for PMI in male patients <75 years old (HR =1.424, $95 \%$ CI: $1.088-1.864$;
P=0.01). However, we did not observe a significant effect in female patients $\geq 75$ years old.

Conclusions: Our study indicates that the PCI-PMI association depends on age and gender groups, $\beta$-blocker use before PCI is associated with increased PMI incidence in male patients $<75$ years old.

Keywords: Percutaneous coronary intervention; periprocedural myocardial injury; $\beta$-blocker; CK-MB; Tn I

Submitted Nov 28, 2020. Accepted for publication Mar 18, 2021.

doi: 10.21037/apm-20-2355

View this article at: http://dx.doi.org/10.21037/apm-20-2355 


\section{Introduction}

Percutaneous coronary intervention (PCI) is considered one of the most effective revascularization methods in treating coronary artery disease patients (CAD). Among patients who undergo PCI, there is approximately a $5 \%$ to $30 \%$ chance for periprocedural myocardial injury (PMI) (1). Patients with PMI are known to have worse clinical outcomes. Recent clinical studies show that PMI is one of the leading causes of mortality and other cardiac abnormalities (2-4). Generally, the occurrence of PMI can be silent and is mainly monitored by elevated myocardial enzymes $(5,6)$.

For patients with coronary artery diseases, especially those with left ventricular dysfunction, $\beta$-blockers are recommended as the first and secondary pretreatment choices. $\beta$-blockers have been a successful treatment option as they can decrease cardiac remodeling, development of arrhythmias, and heart's oxygen demand. In acute myocardial infarction, the timely use of $\beta$-blockers can reduce the infarct size by approximately $20 \%(7,8)$. Nevertheless, reports have shown that concurrent use of $\beta$-blockers with PCI reduces the creatine kinase $\mathrm{MB}$ (CK-MB), which can prolong long-term survival (9-11). However, these reports did not consider certain important factors such as renal dysfunction, heart failure, number of stents implanted, and TIMI flow, which can cause PMI incidence. A previous observational study found that $\beta$-blocker therapy before PCI did not attenuate the postprocedural $\mathrm{CK}-\mathrm{MB}$ rise, which do not support the contention that $\mathrm{BB}$ use before PCI decreases myocardial injury (12). This contradicts the notion that $\beta$-blockers can reduce myonecrosis after PCI. Hence, it is still uncertain whether the use of $\beta$-blocker before PCI can influence PMI incidence, defined as rising CK-MB or troponin I (TnI) levels during the perioperative period.

Previous study has reported several risk factors for PMI, including more extensive disease, multivessel disease, complex lesion morphology, coronary thrombus and calcification, left ventricular systolic dysfunction and urgent procedures. Previous studies have suggested that the incidence of coronary vascular injury complications was higher in women than in men, particularly in patients $<55$ years [odds ratio (OR) 2.74, 95\% confidence interval (CI): 1.49 to 5.04] (13). Older age has also been identified as a risk factor for PMI $(13,14)$. Two-thirds of cardiovascular deaths occurred in people aged over 75 years old (15), with a higher risk of mortality and major adverse cardiovascular events (MACE) rates after PCI compared with those below 75 years old $(16,17)$. Therefore, it is vital to recognize the effect of age when investigating PCI-related disease. In this study, we assessed the relationship between pre-usage of $\beta$-blockers before elective PCI and the PMI incidence in subgroups of patients stratified by gender and age (75 years cut-off point).

We present the following article in accordance with the STROBE reporting checklist (available at http://dx.doi. org/10.21037/apm-20-2355).

\section{Methods}

\section{Patients}

Between January 2015 to November 2018, 5732 patients treated with elective PCI were recruited at Sir Run Run Shaw Hospital, School of Medicine, Zhejiang University. Similar to previous studies $(18,19)$, we excluded patients with elevated CK-MB or TnI levels before the procedure ( $\geq 1 \times$ upper limits of normal (ULN) levels) and adverse cardiovascular events, such as persistent refractory closure of coronary artery induced death or MI with or without emergency bypass surgery. Patients with renal or cardiac dysfunction (eGFR $\leq 30 \mathrm{~mm} / \mathrm{min} / 1.73 \mathrm{~m}^{2}$ or NTproBNP $\geq 2,000 \mathrm{pg} / \mathrm{mL}$ ) were also excluded. There were no exclusion criteria regarding medications taken. This is because there is no supporting evidence on any specific medication before PCI influencing the incidence of PMI. A total of 4,027 patients were finally included in the study. Patients were then divided into four subgroups based on their gender and age of 75 years old. Baseline history, procedures, and medications were recorded. The study was conducted in accordance with the Declaration of Helsinki (as revised in 2013). The study was approved by Institutional Ethics Committee of Sir Run Run Shaw Hospital, School of Medicine, Zhejiang University (NO: 20200803-34) and individual consent for this retrospective analysis was waived.

\section{Study procedures}

All patients underwent a baseline 12-lead ECG examination 24-h before the procedure. Blood samples were collected to determine serum TnI and CK-MB levels before sheath insertion. All interventions were carried out following the standard protocols. Blood samples were collected regularly every eight hours for the first 24 hours to measure cardiac enzymes after the surgery. Patients also underwent another 
12-lead ECG recording at the end of the procedure. In the event of certain complications such as chest pain, additional ECGs, and blood tests were carried out appropriately. During hospital stay, patients were continuously monitored wirelessly by ECG after PCI. N-terminal proBNP (NTproBNP), estimated glomerular filtration rate (eGFR), and lipid profiles were also determined before the intervention.

\section{Definition of periprocedural myocardial injury (PMI)}

We defined PMI as postprocedural TnI or CK-MB $\geq 5 \times$ ULN given that the baseline levels were normal, as described in the revised diagnosis criteria released in 2012 (6). Serum TnI and CK-MB levels were measured before the procedure, at regular intervals of eight hours after the PCI in the first 24 hours, and in cases of ischemia symptoms. The levels of serum TnI and CK-MB were carried out using chemiluminescence immunoassays and an Elecsys 2010 analyzer from Roche Diagnostics (Indianapolis, Ind). The upper limits for normal cases were set at $<0.11 \mathrm{ng} / \mathrm{mL}$ for TnI and 24 IU/L for CK-MB.

\section{Percutaneous coronary intervention}

Patients receiving PCI were identified based on the ACC/ AHA recommendations. Experienced interventional cardiologists performed all the procedures. Before the intervention, patients were given a loading dose of aspirin or clopidogrel, as previously described (20). All patients were given either $70 \mathrm{U} / \mathrm{kg}$ or $5,000 \mathrm{U}$ bolus of unfractionated heparin prior to the procedure plus a bolus of 2,000 to $3,000 \mathrm{U}$ hourly if the procedure was longer than one hour. The PCI type (primary stenting, stenting, angioplasty, or angioplasty only) was decided according to the needs of the patients. We calculated the total balloon inflation pressures and times according to the technical characteristics of the stent and balloon. Applications of anticoagulants or glycoprotein IIb/IIIa receptor blockers were adjusted to the features of the angiographic lesion or clinical situation by the cardiologist.

Single vessel intervention was defined as conducting the procedure in one native coronary vessel distribution (plus branches), whereas multivessel intervention was defined as conducting the procedure in more than two native coronary vessels. The coronary intervention was defined as a graft, if the procedure was performed with a venous or arterial bypass graft. All features of the lesion and angiographic vessels were recorded after each coronary intervention.
Patients with multiple lesions were categorized based on the lesion complexity. The occurrence of periprocedural events was recorded. Multiple occurrences of a single procedural complication in a single patient were considered as one.

\section{Medical treatment}

Medications were given based on the clinical condition of each patient. This included $\beta$-blockers, aspirin, clopidogrel, ticagrelor, warfarin, statins, fibrates, ezetimibe, angiotensinconverting enzyme inhibitors (ACEI), angiotensin receptor blockers (ARB), and calcium channel blockers (CCB). Throughout the procedure, glycoprotein (GP) IIb/IIIa inhibitor was used when required.

\section{Statistical analysis}

Categorical variables are represented by frequency and percentage. All continuous variables are normally distributed. Continuous variables are represented by mean \pm standard deviation. Categorical variables are represented by chi-square test or Fisher exact test as appropriate. The correlation between $\beta$-blocker therapy and the development of PMI was evaluated using univariable and multivariable logistic regression analysis. $\mathrm{P}<0.05$ was considered statistically significant.

\section{Results}

\section{Baseline characteristics and initial treatments}

The flow chart of the study was shown in Figure 1. Baseline clinical characteristics of the patients in the $\beta$-blocker therapy $(\mathrm{n}=2,059)$ and no $\beta$-blocker therapy $(\mathrm{n}=1,968)$ subgroups are summarized in Table 1. Patients in the $\beta$-blocker therapy subgroup were younger than those patients in the no $\beta$-blocker therapy subgroup $(64.95 \pm 10.53$ vs. $66.18 \pm 10.22$ years, respectively; $\mathrm{P}=0.011)$. Among the $\beta$-blocker therapy subgroup, the prevalence rates of hypertension, diabetes mellitus, previous MI, previous PCI, and acute coronary syndrome (ACS) were significantly higher than the no $\beta$-blocker therapy subgroup. Patients with the $\beta$-blocker therapy subgroup had more elevated triglyceride (TG) levels and body mass index (BMI) compared with the no $\beta$-blocker therapy subgroup. However, the percentage of stable angina symptoms and current smoking as well as levels of low-density lipoprotein-cholesterol (LDL-C), high-density lipoproteincholesterol (HDL-C), and total cholesterol (TC) were all 


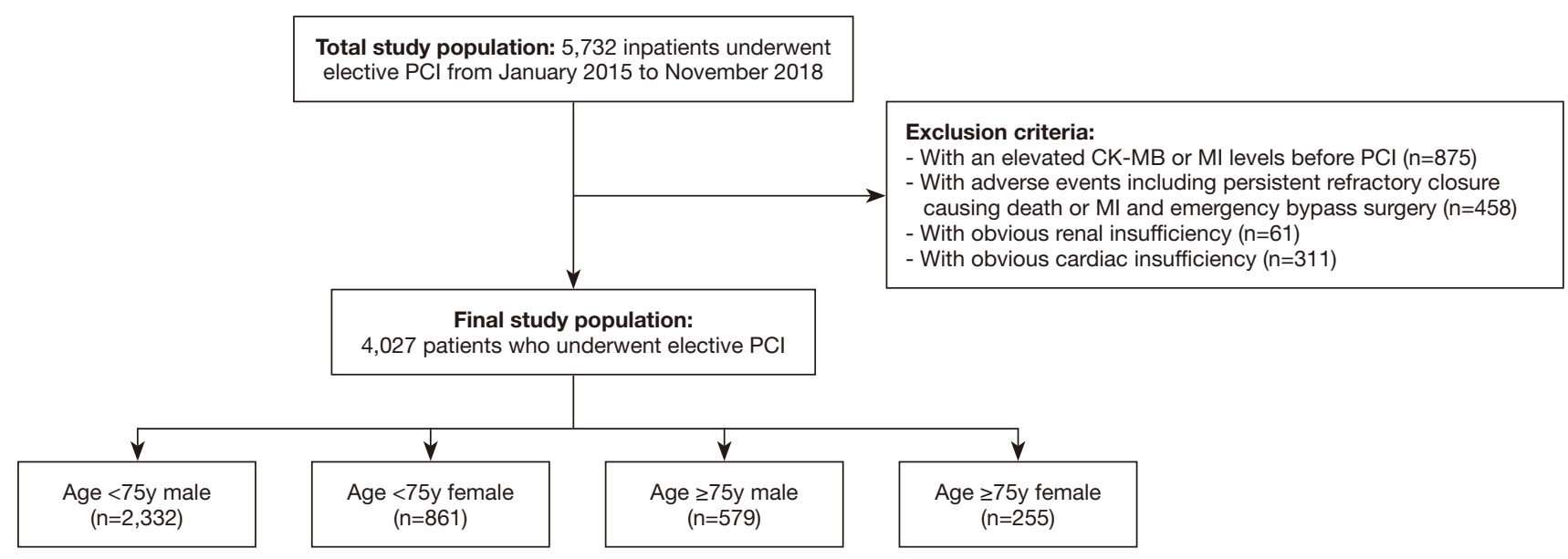

Figure 1 Flow chart of the study. A total of 4,027 patients were enrolled in our study. Patients were further divided into four subgroups according to the age of 75 years old and gender. PCI, percutaneous coronary intervention; CK-MB, creatine kinase-MB; TnI, troponin I; eGFR, estimated glomerular filtration rate; NT-proBNP, N-terminal pro-type-B natriuretic peptide.

Table 1 Baseline characteristics of all patients with and without $\beta$-blocker therapy

\begin{tabular}{|c|c|c|c|c|}
\hline & Total $(n=4,027)$ & Prior $\beta$-blocker therapy $(n=2,059)$ & No $\beta$-blocker therapy $(n=1,968)$ & $P$ value \\
\hline Age (years) & $65.55 \pm 10.40$ & $64.95 \pm 10.53$ & $66.18 \pm 10.22$ & 0.011 \\
\hline $\mathrm{SBP}(\mathrm{mmHg})$ & $132.39 \pm 19.30$ & $131.89 \pm 19.85$ & $132.91 \pm 18.72$ & 0.056 \\
\hline $\mathrm{DBP}(\mathrm{mmHg})$ & $73.47 \pm 12.14$ & $73.19 \pm 12.37$ & $73.75 \pm 11.90$ & 0.067 \\
\hline Diabetes mellitus, $\mathrm{n}(\%)$ & $1,060(26.3)$ & $575(27.9)$ & $485(24.6)$ & 0.013 \\
\hline Heart rate (bpm) & $73.26 \pm 11.79$ & $73.49 \pm 11.78$ & $73.02 \pm 11.80$ & 0.386 \\
\hline Previous MI, n (\%) & $317(7.9)$ & $214(10.4)$ & $103(5.2)$ & $<0.001$ \\
\hline Previous PCI, n (\%) & $1,288(32.0)$ & $758(36.8)$ & $530(26.9)$ & $<0.001$ \\
\hline ACS, n (\%) & $1,663(41.3)$ & $884(42.9)$ & $779(39.6)$ & 0.014 \\
\hline $\begin{array}{l}\text { Asymptomatic myocardial ischemia, } \mathrm{n} \\
(\%)\end{array}$ & $404(10.0)$ & $214(10.4)$ & $190(9.7)$ & 0.373 \\
\hline Cerebrovascular disease, $\mathrm{n}(\%)$ & $340(8.4)$ & $159(7.7)$ & $181(9.2)$ & 0.103 \\
\hline Family history of CHD, n (\%) & $354(8.8)$ & $196(9.5)$ & $158(8.0)$ & 0.081 \\
\hline $\mathrm{BMI}\left(\mathrm{kg} / \mathrm{m}^{2}\right)$ & $24.75 \pm 3.21$ & $24.93 \pm 3.18$ & $24.56 \pm 3.23$ & $<0.001$ \\
\hline Current smoking, n (\%) & 906 (22.5) & $426(20.7)$ & $480(24.4)$ & 0.009 \\
\hline \multicolumn{5}{|l|}{ Laboratory data } \\
\hline
\end{tabular}

Table 1 (continued) 
Table 1 (continued)

\begin{tabular}{|c|c|c|c|c|}
\hline & Total $(n=4,027)$ & Prior $\beta$-blocker therapy $(n=2,059)$ & No $\beta$-blocker therapy $(n=1,968)$ & $P$ value \\
\hline Total cholesterol (mg/dL) & $3.98 \pm 1.16$ & $3.87 \pm 1.08$ & $4.1 \pm 1.23$ & $<0.001$ \\
\hline Triglyceride (mg/dL) & $1.65 \pm 1.31$ & $1.70 \pm 1.15$ & $1.61 \pm 1.11$ & 0.001 \\
\hline hs-CRP (mg/dL) & $3.91 \pm 9.33$ & $3.98 \pm 9.18$ & $3.84 \pm 9.50$ & 0.177 \\
\hline eGFR $\left[\mathrm{mL} /\left(\min \cdot 1.73 \mathrm{~m}^{2}\right)\right]$ & $86.41 \pm 21.45$ & $86.10 \pm 21.99$ & $86.74 \pm 20.88$ & 0.228 \\
\hline \multicolumn{5}{|l|}{ Medication, n (\%) } \\
\hline Aspirin & 3,917 (97.3) & $2,014(97.8)$ & $1,903(96.7)$ & 0.030 \\
\hline Clopidogrel & $3,790(94.1)$ & $1,912(92.9)$ & $1,878(95.4)$ & 0.001 \\
\hline Statins & $3,939(98.4)$ & $2,024(98.3)$ & $1,915(97.3)$ & 0.031 \\
\hline Fibrates & $25(0.6)$ & $13(0.6)$ & $12(0.6)$ & 0.930 \\
\hline Ezetimibe & $339(8.4)$ & $187(9.1)$ & $152(7.7)$ & 0.121 \\
\hline ACEI & $950(23.6)$ & $572(27.8)$ & $378(19.2)$ & $<0.001$ \\
\hline ARB & $1,307(32.5)$ & $689(33.5)$ & $618(31.4)$ & 0.163 \\
\hline CCB & 1,262 (31.3) & 594 (28.8) & 668 (33.9) & $<0.001$ \\
\hline
\end{tabular}

Data are presented as mean \pm SD or $n(\%)$. The $\mathrm{P}$ values for continuous data were obtained from the analysis of the unpaired $t$-test, the $\mathrm{P}$ values for categorical data were obtained from the chi-square test. SBP, systolic blood pressure; DBP, diastolic blood pressure; MI, myocardial infarction; $\mathrm{PCl}$, percutaneous coronary intervention; CABG, coronary artery bypass grafting; ACS, acute coronary syndrome; BMI, body mass index; CHD, coronary heart disease; LDL-C, low-density lipoprotein-cholesterol; HDL-C, high-density lipoprotein-cholesterol; hs-CRP, high-sensitivity $\mathrm{C}$ reactive protein; eGFR, estimated glomerular filtration rate; ACEI, angiotensin-converting enzyme inhibitor; ARB, angiotensin II receptor blockage; CCB, calcium channel blocker.

significantly lower in the $\beta$-blocker therapy subgroup. Other clinical variables had no significant differences between the two subgroups, including blood pressure, heart rate, previous coronary artery bypass grafting (CABG) history, asymptomatic myocardial ischemia, cerebrovascular disease, family history of coronary heart disease (CHD), platelet, high-sensitivity $\mathrm{C}$ reactive protein (hs-CRP), serum creatinine, and estimated glomerular filtration rate (eGFR).

Medications were also recorded and presented in Table 1. Patients in the $\beta$-blocker therapy subgroup have a higher proportion taking aspirin, ticagrelor, statins, and ACEI. Conversely, a higher percentage of the patients taking clopidogrel and CCB were found in the no $\beta$-blocker therapy subgroup. There were no differences in other medications such as warfarin, fibrates, ezetimibe, and ARB.

\section{PCI-related angiographic and procedural characteristics}

A comparison of PCI-related angiographic and procedural characteristics is shown in Table 2. As shown, patients receiving prior $\beta$-blocker therapy have a larger proportion of calcification, chronic total occlusions (CTO) lesion, and thrombus at baseline, compared with no prior $\beta$-blocker therapy patients. The percentage of post-dilatation was lower in the $\beta$-blocker therapy subgroup, compared to no $\beta$-blocker therapy subgroup. During the procedures, there were no significant differences in the lesion location, multivessel intervention, ACC/AHA type B2/C lesions, lesion length $(\geq 20 \mathrm{~mm})$, bifurcation lesions, eccentric lesions and CTO lesions, angulated lesions, pre-procedural TIMI flow $<3$, post-procedural TIMI flow $<3$, lesion diameter $(\geq 2.5 \mathrm{~mm})$, number of implanted stents, mean 
Table 2 Angiographic \& procedural characteristics of all patients with and without $\beta$-blocker therapy.

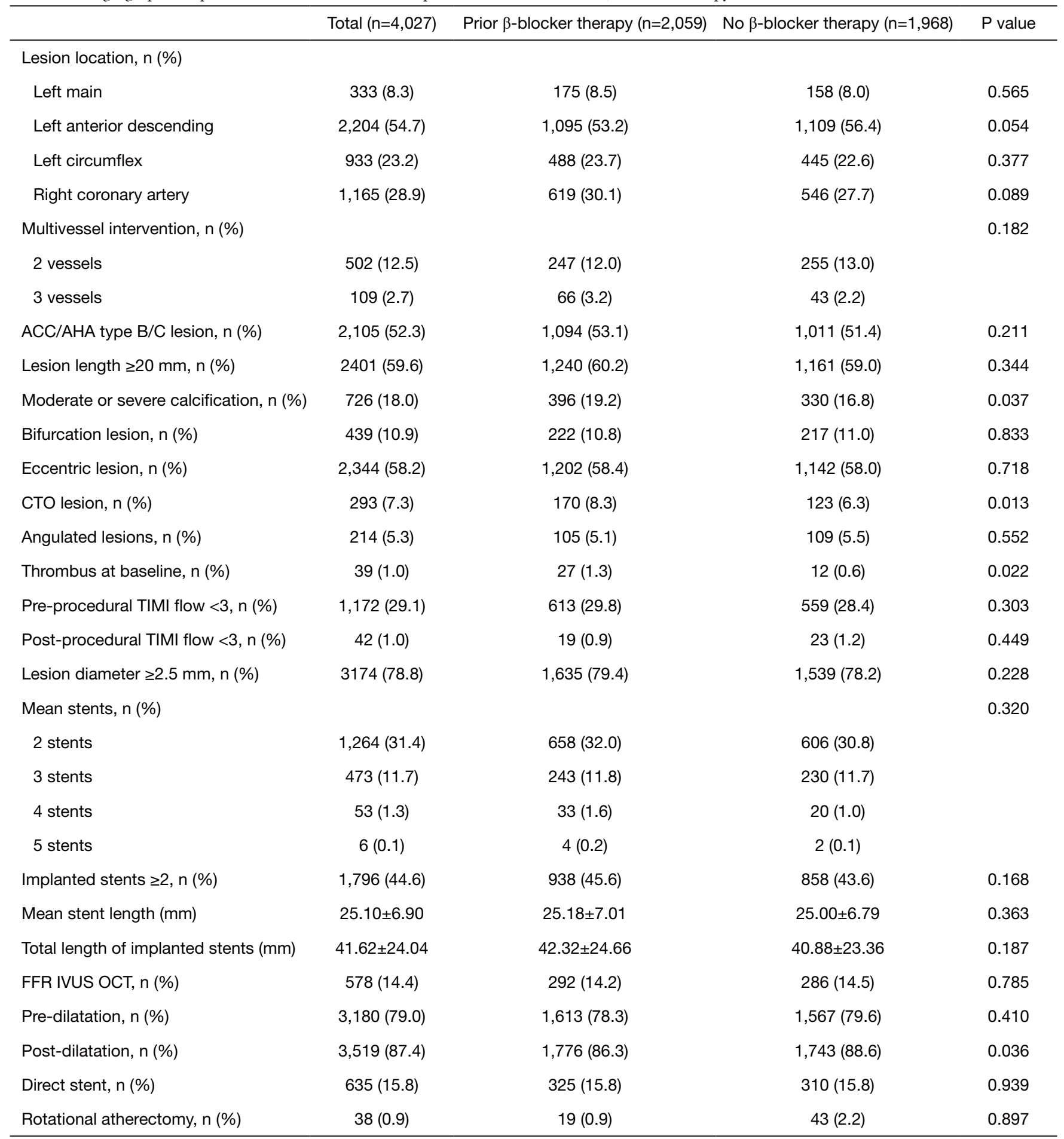

Data are presented as mean \pm SD or $n(\%)$. ACC/AHA, American College of Cardiology/American Heart Association; CTO, chronic total occlusions; TIMI, thrombolysis in myocardial infarction; FFR, fractional flow reserve; IVUS, intravenous ultrasound; OCT, optical coherence tomography. 

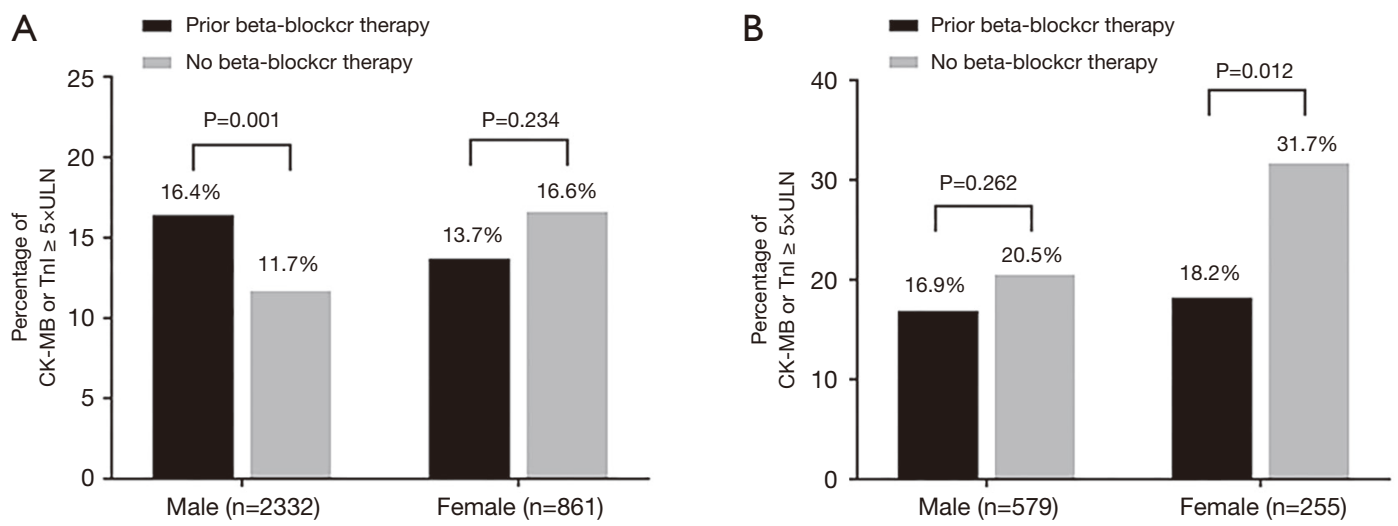

Figure 2 Comparison of the incidence of PMI in prior $\beta$-blocker therapy subgroup and no $\beta$-blocker therapy subgroup in patients $<75$ years old grouping by gender, and patients $\geq 75$ years old grouping by gender. (A) Comparison of the incidence of CK-MB or TnI increase $\geq 5 \times$ ULN between prior $\beta$-blocker therapy subgroup and no $\beta$-blocker therapy subgroup of patients below 75 years old. Among the 2,332 male patients, prior $\beta$-blocker therapy subgroup has a higher percentage of CK-MB or TnI $\geq 5 \times$ ULN than the no $\beta$-blocker therapy subgroup (16.4\% $v$ s. $11.7 \%, \mathrm{P}=0.001$ ). There were no significant differences between the two groups of 861 female patients. (B) Comparison of the incidence of CK$\mathrm{MB}$ or $\mathrm{TnI}$ increase $\geq 5 \times \mathrm{ULN}$ between the prior $\beta$-blocker therapy subgroup and no $\beta$-blocker therapy subgroup of the patients over 75 years old. Among the 255 female patients, prior $\beta$-blocker therapy subgroup has a lower percentage of CK-MB or TnI $\geq 5 \times \mathrm{ULN}$ than the no prior $\beta$-blocker therapy subgroup $(18.2 \%$ vs. $31.7 \%, \mathrm{P}=0.012)$. There were no significant differences between two groups of 579 male patients.

stent length, the total length of implanted stents, direct stent, intracranial plaque resection, the proportion of receiving IVUS, OCT, or FFR, and pre-dilatation. Results among the study population stratified by gender and age of 75 are shown in Tables S1,S2.

\section{The incidence of PMI following elective PCI}

Several reports have suggested an increase in the cardiac $\mathrm{TnI}$ or CK-MB in a proportion of patients ranging from less than $10 \%$ to almost $50 \%$ after PCI. In our study, the percentage of PMI in male patients $<75$ years was higher in those receiving prior $\beta$-blocker therapy (16.4\%), compared to those who had not (11.7\%), as shown in Figure $2 A$. However, in female patients $<75$ years old and male patients $\geq 75$ years old, PMI percentage had no significant differences among patients with or without a prior $\beta$-blocker therapy, as shown in Figure $2 A$ and $2 B$. Interestingly, for the female patients $\geq 75$ years old, the proportion of PMI was lower in the therapy subgroup (18.2\%) compared with the non-therapy (31.7\%) subgroup, as shown in Figure $2 B$.

\section{Logistic regression analysis of the potential risk factors for PMI}

The covariates in the univariable and multivariable analysis for predictors of PMI included prior $\beta$-blocker treatment, previous MI, previous PCI, hypertension, diabetes mellitus, platelet, heart rate, BMI, stable angina pectoris (SAP) or ACS, current smoking, total length of implanted stents, ACC/AHA type B/C lesions, pre-dilatation, and postdilatation.

The univariable and multivariable analysis for predictors of PMI for all patients are shown in Table 3. In both univariable and multivariable analysis, patients $\geq 75$ years, heart rate, total length of implanted stents, type B/C lesion and pre-dilatation or post-dilatation associated with the higher incidence of PMI.

The logistic regression analysis results for $\mathrm{PMI}$ incidence in patients $<75$ years are shown in Table 4. In male patients, prior $\beta$-blocker therapy (HR $=1.424,95 \%$ CI: $1.088-1.864$, $\mathrm{P}=0.010)$, previous $\mathrm{MI}$ (HR $=1.638$, 95\% CI: 1.052 2.551, $\mathrm{P}=0.029)$, and the total length of implanted stents $(\mathrm{HR}=1.027,95 \% \mathrm{CI}: 1.022-1.032, \mathrm{P}<0.001)$ remained significantly associated with the incidence of PMI after elective PCI. However, in female patients, only heart rate (HR $=1.022,95 \% \mathrm{CI}: 1.005-1.040, \mathrm{P}=0.011)$ and the total length of implanted stents (HR $=1.020,95 \%$ CI: $1.011-$ $1.028, \mathrm{P}<0.001)$ were significant.

Table 5 shows the logistic regression analysis results for related risk factors for PMI in patients $\geq 75$ years. After adjustment, for both male and female patients $\geq 75$ years, 
Table 3 Univariable and Multivariable analysis for predictors of PMI

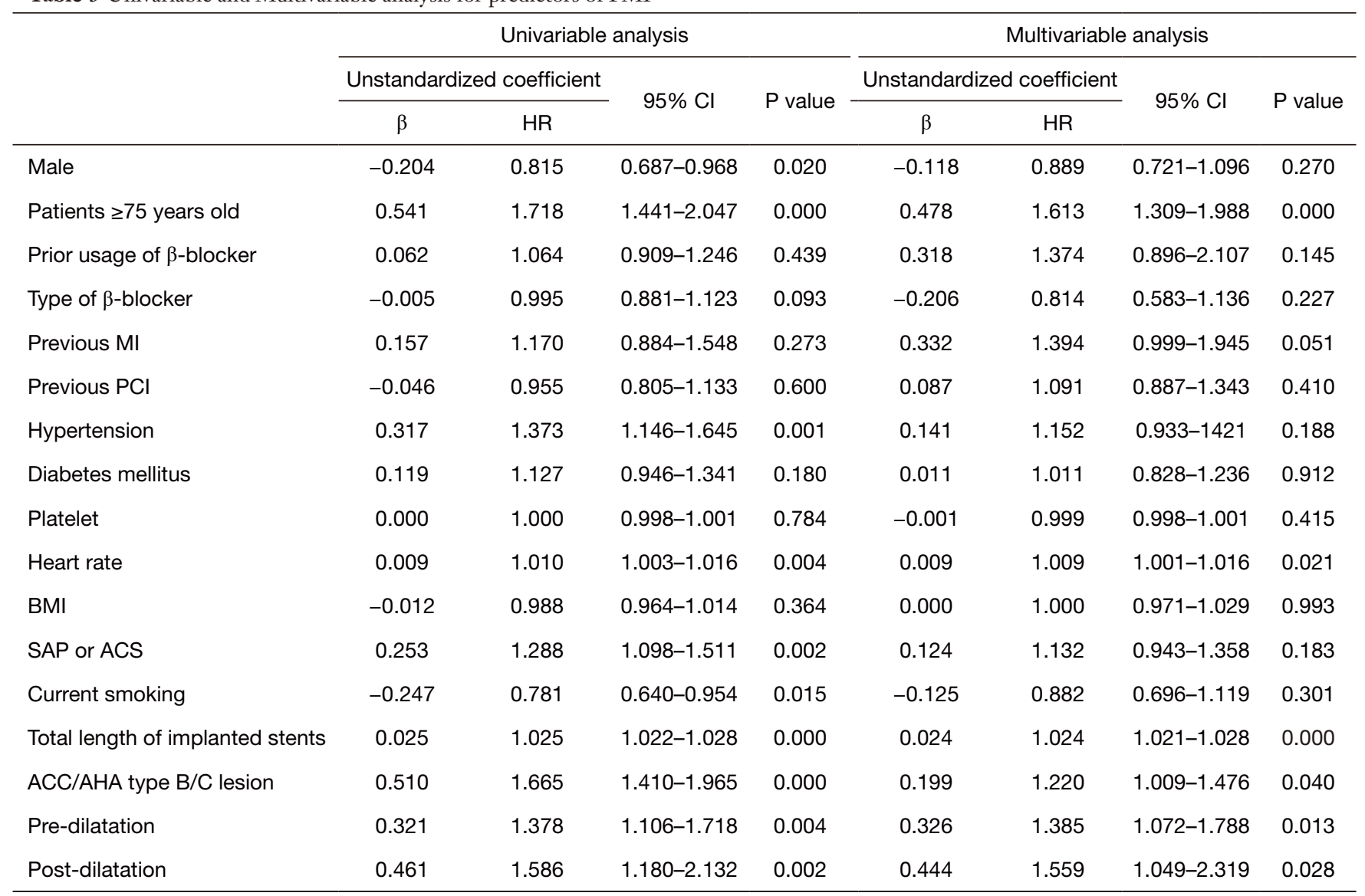

$\mathrm{HR}$, hazard ratio; MI, myocardial infarction; $\mathrm{PCl}$, percutaneous coronary intervention; BMI, body mass index; SAP, stable angina pectoris; ACS, acute coronary syndrome; ACC/AHA, American College of Cardiology/American Heart Association.

only total length of implanted stents were associated with the PMI incidence ( $\mathrm{HR}=1.025,95 \% \mathrm{CI}: 1.015-1.035$, $\mathrm{P}<0.001 ; \mathrm{HR}=1.028,95 \%$ CI: $1.012-1.044, \mathrm{P}=0.001$, respectively). Interestingly, we also found that the incidence of PMI after elective PCI in female patients $\geq 75$ years was significantly lower in the $\beta$-blocker therapy subgroup. However, after the adjustment, prior $\beta$-blocker was not associated with the PMI incidence.

\section{Logistic regression analysis of the potential risk factors for PMI among patients using metoprolol}

In our study, only metoprolol and bisoprolol were used among all patients. Since over $80 \%$ of patients used metoprolol before elective PCI in the $\beta$-blocker therapy subgroup (Figure S1), we further performed logistic regression analysis among metoprolol users (Tables S3 and S4). The potential risk factors were the same as mentioned above. Similar to the previous results, prior $\beta$-blocker $(\mathrm{HR}=1.475,95 \% \mathrm{CI}: 1.116-1.951, \mathrm{P}=0.006)$ remained a significant independent risk factor for PMI for the male patients below 75 years old after the adjustment. Meanwhile, the total length of implanted stents was the only risk factor for PMI incidence regardless of age and sex.

\section{Discussion}

In the current study, we found that male patients, elder people $(\geq 75$ years old), total length of the implanted stents, ACC/AHA type B/C lesion, per and post dilatation were all the significant risk factors in the Univariable and Multivariable analysis for predictors of PMI. PMI incidence was higher among male patients $<75$ years old treated with beta-blockers. A contrary finding was observed 
Table 4 Logistic regression analysis for predictors of PMI in the patients $<75$ years old

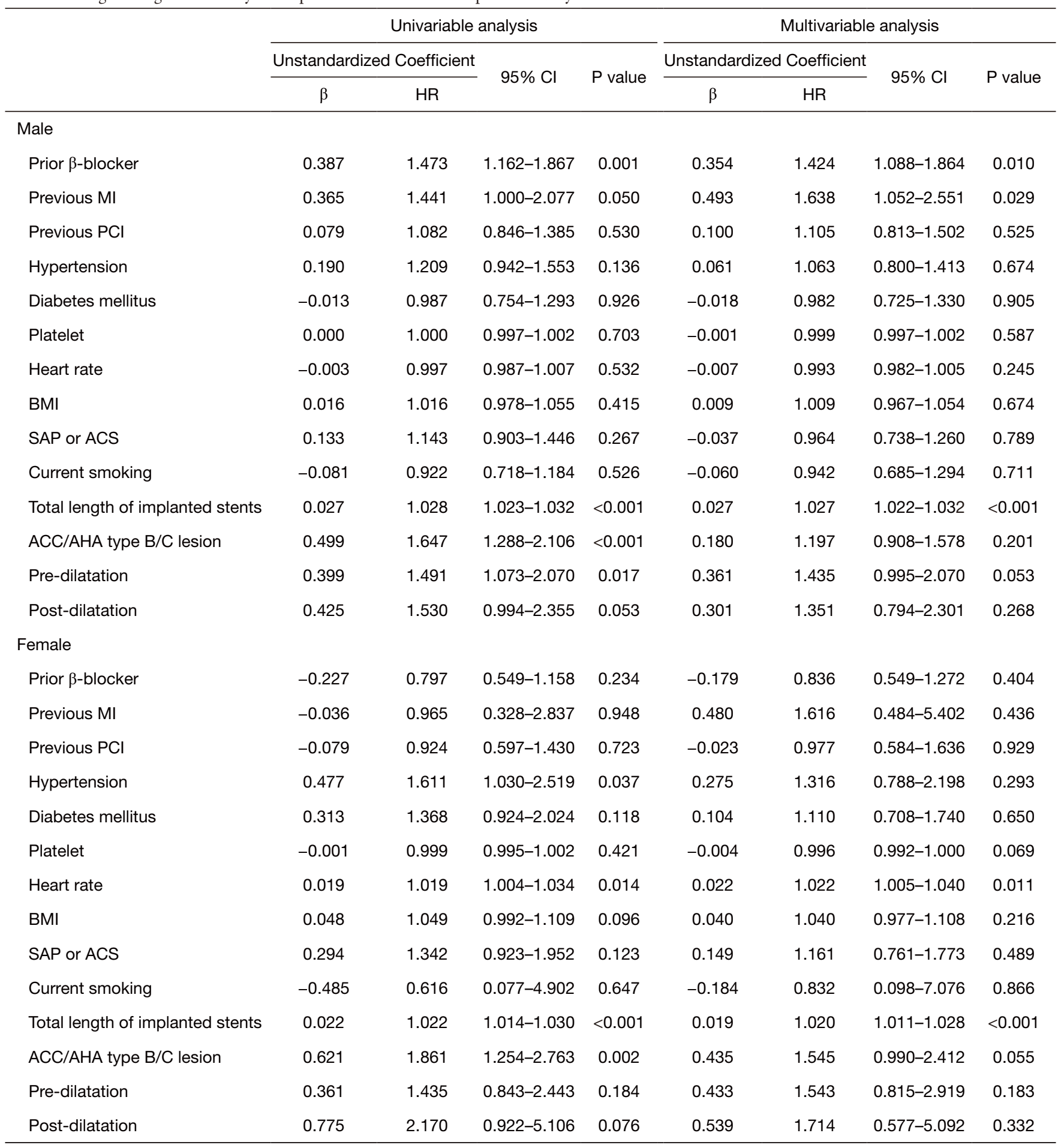

HR, hazard ratio; MI, myocardial infarction; PCl, percutaneous coronary intervention; BMI, body mass index; SAP, stable angina pectoris; ACS, acute coronary syndrome; ACC/AHA, American College of Cardiology/American Heart Association. 
Table 5 Logistic regression analysis for predictors of PMI in the patients $\geq 75$ years old

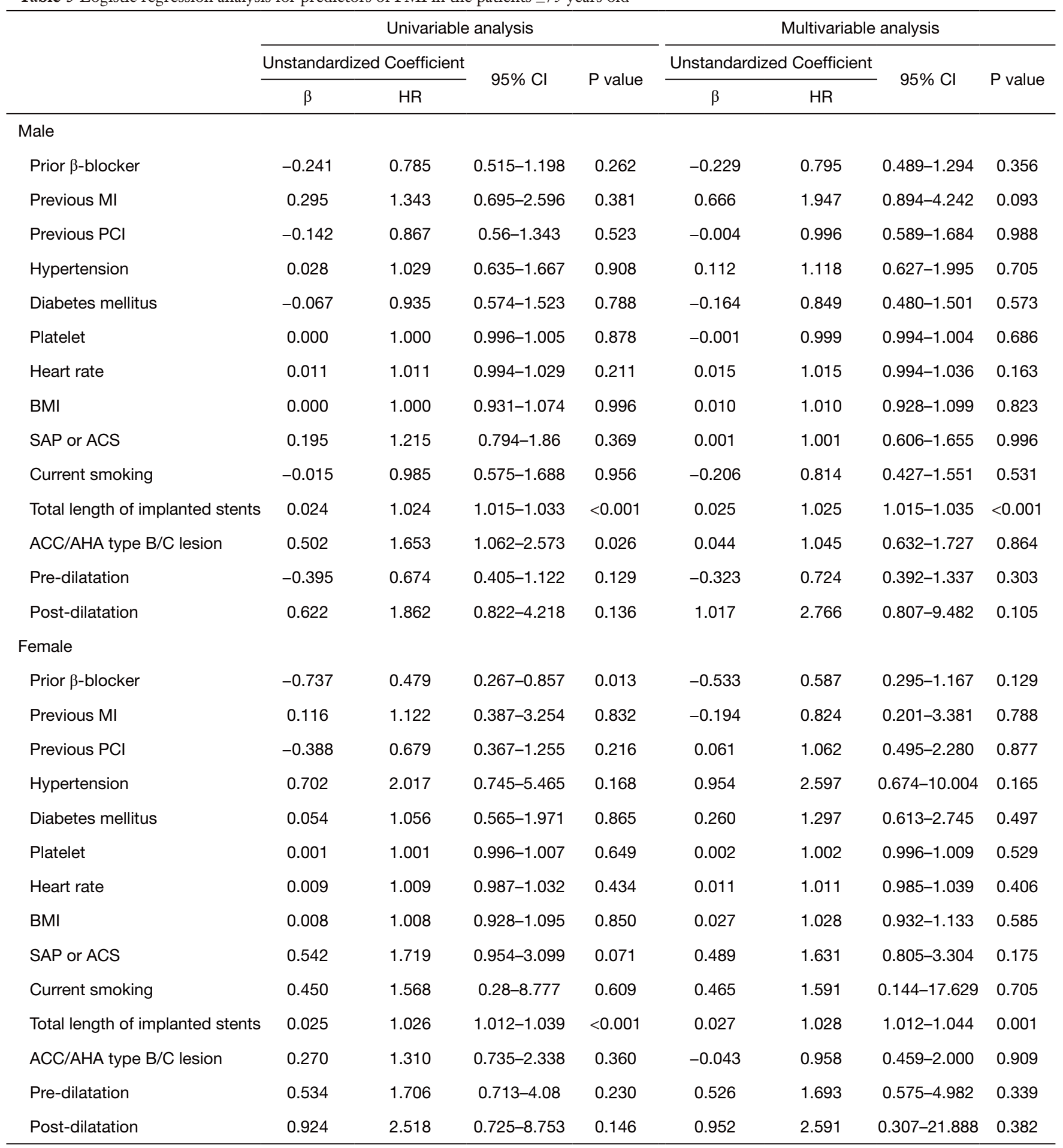

$\mathrm{HR}$, hazard ratio; MI, myocardial infarction; PCl, percutaneous coronary intervention; BMI, body mass index; SAP, stable angina pectoris; ACS, acute coronary syndrome; ACC/AHA, American College of Cardiology/American Heart Association. 
among female patients $\geq 75$ years old. However, in female patients $<75$ years old and male patients $\geq 75$ years old, PMI incidence was not different between the two groups. We further performed a logistic regression analysis for identifying any potential risk factors for the incidence of PMI. After adjustment, we found that the total length of implanted stents was the risk factor for PMI incidence in all patients. Furthermore, prior use of $\beta$-blocker was significantly associated with PMI incidence in old male patients $<75$ years. The protective effect of a prior $\beta$-blocker application for the incidence of PMI in female patients $\geq 75$ years old was not observed in this model. Furthermore, we performed a logistic analysis by comparing the patients taking metoprolol with those in the no prior $\beta$-blocker therapy subgroup, and we found similar results.

Several studies have suggested that PCI is accompanied by some cardiac complications, including repeat revascularization, myocardial reinfarction, and fatality $(1,21,22)$. The occurrence of PMI is usually related to a worse prognosis after PCI. The levels of CK-MB and TnI reveal the extent of enzymes release and the degree of myocardial injury $(23,24)$. Several factors could explain the risk of PMI, including patient-related factors, such as age; lesion-related factors, such as chronic total occlusion; and proceduralrelated factors, such as the number of stents implanted (25). PMI can also be caused by overactivation of the sympathetic system, which triggers hypertension, tachycardia, and an increase in myocardial oxygen demand (26).

$\beta$-blocker therapy works by suppressing the activity of the sympathetic system. It decreases arrhythmias, ischemia, myocardial infarction, the release of cardiac enzymes, and limits the infarct size as revealed in several prospective randomized trials and retrospective studies (27-29). It also lowers the heart rate, which in turn reduces oxygen consumption during coronary intervention. Therefore, it can prevent cardiovascular events in patients undergoing therapy. However, the efficacy of the $\beta$-blocker application before coronary intervention is still controversial as it may lead to some procedural events, such as spasm and slow flow of the coronary artery. This is associated with high coronary vascular resistance due to sympathetic blockade.

The main type of $\beta$-blockers used in our study was metoprolol. Our results of the association between metoprolol and PMI incidence suggest that prior metoprolol therapy might induce a higher risk of PMI in male patients below 75 years old. From a pharmacology perspective, metoprolol application before PCI might over-activate the $\alpha$-receptor of the coronary arteries when the $\beta$-receptors are suppressed. The over-activated $\alpha$-receptors make the coronary arteries prone to the effect of vasoconstriction. Besides, the use of metoprolol reduces the myocardial contractility and oxygen consumption of the heart. The level of adenosine, which is generated by myocardial contractility, is also decreased. Adenosine is known to dilate the coronary artery and attenuate the effect of $\beta$-adrenergic receptors (30). So, metoprolol use before PCI might eventually induce the microvascular contraction of the coronary arteries.

Microvascular dysfunction is one of the main reasons to make patients prone to PMI incidence $(31,32)$. Therefore, we assumed there were two possible reasons to explain such adverse effect of $\beta$-blockers on the incidence of PMI only existing among the male patients $<75$ years old. First, the sympathetic activity decreases as age grows. The response to $\beta$-blockers is much higher in younger patients $(33,34)$. Pre-usage of $\beta$-blockers before PCI has a more significant impact on the heart rate, blood pressure, and microcirculation among patients $<75$ years old than the patients $\geq 75$ years old. Pre-usage of $\beta$-blockers before PCI might lead to over-reaction of coronary microcirculation during or after the surgery, which can induce spasm and slow coronary artery flow. Second, as shown in Table S1, the proportion of smoking $(33.6 \%)$ was highest in male patients $<75$ years old. Smoking is another risk factor that can cause a spasm of microcirculation. It might exacerbate the condition and make patients more susceptible to the incidence of PMI.

It is still unclear whether pre-procedural $\beta$-blocker therapy modulates the incidence of PMI. Our results agree with the findings reported by Ellis et al. (12), but in contrast to Sharma et al. (35). Ellis et al. support the contention that $\beta$-blockers use before PCI does not attenuate postprocedural myocardial injury. However, Sharma et al. showed that prior $\beta$-blocker therapy had a cardioprotective effect by reducing CK-MB levels after PCI and was associated with lower mortality at a one-year follow-up.

There may be some reasons for the conflicting conclusions from various studies on this matter. First, patients enrolled in these studies displayed distinct differences. In the study by Sharma et al., $57 \%$ of patients received rotational atherectomy, in contrast to only $0.9 \%$ in the present study, which is below the national average (36). Rotational atherectomy may trigger "no flow" and "slow flow" and cause an increase of CK-MB or TnI $(37,38)$. However, values of these cardiac enzymes $\geq 5 \times$ ULN reported previously were higher, compared to the current 
study (2.4\% vs. $15.7 \%)$. Second, CK-MB was measured before the procedure in their study, and hence, a few values were missed. In our study, TnI and CK-MB in all patients were obtained without missing values. Another important factor could be that different clinical and procedural characteristics were included as covariates in the logistic regression analysis. Sharma et al. did not measure factors that could influence CK-MB or TnI levels, which were assessed in our study, such as previous MI, previous PCI, and the total length of implant stents.

Our study provides new insights into the association between $\beta$-blocker use before the intervention and PMI incidence. Although the benefit of $\beta$-blocker in reducing long-term adverse cardiovascular events has been thoroughly investigated, its use during surgery still needs to be evaluated based on the characteristics of each patient.

\section{Limitations}

There were several limitations to this study. First, this was a retrospective observational study, so the allocation to $\beta$-blocker therapy was not randomly assigned. There were substantial differences recognized between patients treated with or without $\beta$-blockers. Second, our propensity analysis for the use of $\beta$-blockers was only modestly predictive. It is perhaps not surprising because only half of the patients received $\beta$-blockers. In other studies, the proportion of patients using $\beta$-blocker therapy was much higher. Third, the proportion of patients who had complications during the procedure was relatively lower than that reported by other studies. Additionally, our study excluded patients with elevated TnI or CK-MB pre-procedure, and hence, the conclusion may not be generalizable to ACS patients with high myocardial makers. Lastly, we only performed secondary analysis for the association between metoprolol and PMI incidence but not bisoprolol due to lack of statistical power. Therefore, the way of how our findings apply to clinical practice still needs further evaluation.

\section{Conclusions}

This study investigated the risk factors for PMI incidence after elective PCI and found that the total length of implanted stents was significantly associated with PMI incidence in all patients. More importantly, prior usage of $\beta$-blocker before PCI was associated with increased PMI incidence in male patients $<75$ years old.

\section{Acknowledgments}

The authors would like to express their gratitude to EditSprings (https://www.editsprings.com/) for the expert linguistic services provided.

Funding: This work was supported by the Natural Science Foundation of Zhejiang Province (LY18H020007 and LQ16H020001) and the National Natural Science Foundation of China (81800212 and 81570246). The funders had no role in study design, data collection and analysis, manuscript preparation, or decision to publish.

\section{Footnote}

Reporting Checklist: The authors have completed the STROBE reporting checklist. Available at http://dx.doi. org/10.21037/apm-20-2355

Data Sharing Statement: Available at http://dx.doi. org/10.21037/apm-20-2355

Conflicts of Interest: All authors have completed the ICMJE uniform disclosure form (available at http://dx.doi. org/10.21037/apm-20-2355). The authors have no conflicts of interest to declare.

Ethical Statement: The authors are accountable for all aspects of the work in ensuring that questions related to the accuracy or integrity of any part of the work are appropriately investigated and resolved. The study was approved by Institutional Ethics Committee of Sir Run Run Shaw Hospital, School of Medicine, Zhejiang University (NO: 20200803-34) and individual consent for this retrospective analysis was waived.

Open Access Statement: This is an Open Access article distributed in accordance with the Creative Commons Attribution-NonCommercial-NoDerivs 4.0 International License (CC BY-NC-ND 4.0), which permits the noncommercial replication and distribution of the article with the strict proviso that no changes or edits are made and the original work is properly cited (including links to both the formal publication through the relevant DOI and the license). See: https://creativecommons.org/licenses/by-nc-nd/4.0/.

\section{References}

1. Jeremias A, Kleiman NS, Nassif D, et al. Prevalence and 
prognostic significance of preprocedural cardiac troponin elevation among patients with stable coronary artery disease undergoing percutaneous coronary intervention: results from the evaluation of drug eluting stents and ischemic events registry. Circulation 2008;118:632-8.

2. Ben-Yehuda O, Chen S, Redfors B, et al. Impact of large periprocedural myocardial infarction on mortality after percutaneous coronary intervention and coronary artery bypass grafting for left main disease: an analysis from the EXCEL trial. Eur Heart J 2019;40:1930-41.

3. Jaguszewski M, Gilis-Malinowska N, GutierrezChico JL, et al. Periprocedural Myocardial Injury After Recanalization of Single Chronic Coronary Occlusion - A Propensity Score Analysis Comparing Long-Term Clinical Outcomes. J Invasive Cardiol 2017;29:63-7.

4. Jang WJ, Yang JH, Choi SH, et al. Association of periprocedural myocardial infarction with long-term survival in patients treated with coronary revascularization therapy of chronic total occlusion. Catheter Cardiovasc Interv 2016;87:1042-9.

5. Cuculi F, Lim CC, Banning AP. Periprocedural myocardial injury during elective percutaneous coronary intervention: is it important and how can it be prevented? Heart 2010;96:736-40.

6. Thygesen K, Alpert JS, Jaffe AS, et al. Third universal definition of myocardial infarction. Circulation 2012;126:2020-35.

7. Chatterjee S, Chaudhuri D, Vedanthan R, et al. Early intravenous beta-blockers in patients with acute coronary syndrome--a meta-analysis of randomized trials. Int J Cardiol 2013;168:915-21.

8. Wang FW, Osman A, Otero J, et al. Distal myocardial protection during percutaneous coronary intervention with an intracoronary beta-blocker. Circulation 2003;107:2914-9.

9. Er F, Dahlem KM, Nia AM, et al. Randomized Control of Sympathetic Drive With Continuous Intravenous Esmolol in Patients With Acute ST-Segment Elevation Myocardial Infarction: The BEtA-Blocker Therapy in Acute Myocardial Infarction (BEAT-AMI) Trial. JACC Cardiovasc Interv 2016;9:231-40.

10. Chen ZW, Qian JY, Ma JY, et al. Risk factors of cardiac troponin $\mathrm{T}$ elevation in patients with stable coronary artery disease after elective coronary drug-eluting stent implantation. Clin Cardiol 2011;34:768-73.

11. Kini AS, Lee P, Marmur JD, et al. Correlation of postpercutaneous coronary intervention creatine kinase$\mathrm{MB}$ and troponin I elevation in predicting mid-term mortality. Am J Cardiol 2004;93:18-23.

12. Ellis SG, Brener SJ, Lincoff AM, et al. beta-blockers before percutaneous coronary intervention do not attenuate postprocedural creatine kinase isoenzyme rise. Circulation 2001;104:2685-8.

13. Argulian E, Patel AD, Abramson JL, et al. Gender differences in short-term cardiovascular outcomes after percutaneous coronary interventions. Am J Cardiol 2006;98:48-53.

14. Zhang D, Li Y, Yin D, et al. Risk stratification of periprocedural myocardial infarction after percutaneous coronary intervention: Analysis based on the SCAI definition. Catheter Cardiovasc Interv 2017;89:534-40.

15. Mozaffarian D, Benjamin EJ, Go AS, et al. Heart Disease and Stroke Statistics-2016 Update: A Report From the American Heart Association. Circulation 2016;133:e38-360.

16. Zheng X, Li JJ, Yuan JQ, et al. Coronary intervention in patients $>$ or $=75$ years old with ST-elevation myocardial infarction: in-hospital and 6-month clinical outcomes. Chin Med J (Engl) 2010;123:2171-5.

17. De Felice F, Fiorilli R, Parma A, et al. Comparison of oneyear outcome of patients aged $<75$ years versus $>/=75$ years undergoing "rescue" percutaneous coronary intervention. Am J Cardiol 2011;108:1075-80.

18. Niccoli G, Sgueglia GA, Latib A, et al. Association of baseline C-reactive protein levels with periprocedural myocardial injury in patients undergoing percutaneous bifurcation intervention: a CACTUS study subanalysis. Catheter Cardiovasc Interv 2014;83:E37-44.

19. Zhang Q, Hu J, Yang ZK, et al. Correlates and outcomes related to periprocedural myocardial injury during percutaneous coronary intervention for chronic total occlusion: Results from a prospective, single center PCI registry. Catheter Cardiovasc Interv 2016;87 Suppl 1:616-23.

20. Zhong Z, Liu J, Zhang Q, et al. Relationship Between Preoperative Low-Density Lipoprotein Cholesterol and Periprocedural Myocardial Injury in Patients Following Elective Percutaneous Coronary Intervention in Southern China. Med Sci Monit 2018;24:4154-61.

21. Cavallini C, Savonitto S, Violini R, et al. Impact of the elevation of biochemical markers of myocardial damage on long-term mortality after percutaneous coronary intervention: results of the CK-MB and PCI study. Eur Heart J 2005;26:1494-8.

22. Feldman DN, Kim L, Rene AG, et al. Prognostic value of cardiac troponin-I or troponin-T elevation following 
nonemergent percutaneous coronary intervention: a metaanalysis. Catheter Cardiovasc Interv 2011;77:1020-30.

23. Roe MT, Mahaffey KW, Kilaru R, et al. Creatine kinase$\mathrm{MB}$ elevation after percutaneous coronary intervention predicts adverse outcomes in patients with acute coronary syndromes. Eur Heart J 2004;25:313-21.

24. Feldman DN, Minutello RM, Bergman G, et al. Relation of troponin I levels following nonemergent percutaneous coronary intervention to short- and long-term outcomes. Am J Cardiol 2009;104:1210-5.

25. Prasad A, Herrmann J. Myocardial infarction due to percutaneous coronary intervention. $\mathrm{N}$ Engl J Med 2011;364:453-64.

26. Jerkic H, Letilovic T, Stipinovic M, et al. Association of chronic kidney disease with periprocedural myocardial injury after elective stent implantation: A single center prospective cohort study. Medicine (Baltimore) 2016;95:e5381.

27. Ibanez B, Macaya C, Sanchez-Brunete V, et al. Effect of early metoprolol on infarct size in ST-segmentelevation myocardial infarction patients undergoing primary percutaneous coronary intervention: the Effect of Metoprolol in Cardioprotection During an Acute Myocardial Infarction (METOCARD-CNIC) trial. Circulation 2013;128:1495-503.

28. Pizarro G, Fernandez-Friera L, Fuster V, et al. Long-term benefit of early pre-reperfusion metoprolol administration in patients with acute myocardial infarction: results from the METOCARD-CNIC trial (Effect of Metoprolol in Cardioprotection During an Acute Myocardial Infarction). J Am Coll Cardiol 2014;63:2356-62 .

29. Blessberger H, Kammler J, Domanovits H, et al. Perioperative beta-blockers for preventing surgery-related mortality and morbidity. Cochrane Database Syst Rev 2018;3:CD004476.

30. Reiss AB, Grossfeld D, Kasselman LJ, et al. Adenosine

Cite this article as: Wang M, Lv Q, Wang Y, Wang Y, Lin M, Zhao L, Fu G, Zhang W. $\beta$-blocker use before elective percutaneous coronary intervention as a risk factor for periprocedural myocardial injury incidence in male patients below 75 years old: a single-center retrospective study. Ann Palliat Med 2021;10(5):5055-5068. doi: 10.21037/apm-20-2355 and the Cardiovascular System. Am J Cardiovasc Drugs 2019;19:449-64.

31. Hoole SP, White PA, Heck PM, et al. Primary coronary microvascular dysfunction and poor coronary collaterals predict post-percutaneous coronary intervention cardiac necrosis. Coron Artery Dis 2009;20:253-9.

32. Lerman A, Holmes DR, Herrmann J, et al. Microcirculatory dysfunction in ST-elevation myocardial infarction: cause, consequence, or both? Eur Heart J 2007;28:788-97.

33. Hotta H, Uchida S. Aging of the autonomic nervous system and possible improvements in autonomic activity using somatic afferent stimulation. Geriatr Gerontol Int 2010;10 Suppl 1:S127-36.

34. Barontini M, Lazzari JO, Levin G, et al. Age-related changes in sympathetic activity: biochemical measurements and target organ responses. Arch Gerontol Geriatr 1997;25:175-86.

35. Sharma SK, Kini A, Marmur JD, et al. Cardioprotective effect of prior beta-blocker therapy in reducing creatine kinase-MB elevation after coronary intervention: benefit is extended to improvement in intermediate-term survival. Circulation 2000;102:166-72.

36. Brindis RG, Fitzgerald S, Anderson HV, et al. The American College of Cardiology-National Cardiovascular Data Registry (ACC-NCDR): building a national clinical data repository. J Am Coll Cardiol 2001;37:2240-5.

37. Iwasaki K, Samukawa M, Furukawa H. Comparison of the effects of nicorandil versus verapamil on the incidence of slow flow/no reflow during rotational atherectomy. Am J Cardiol 2006;98:1354-6.

38. Azzalini L, Dautov R, Ojeda S, et al. Long-term outcomes of rotational atherectomy for the percutaneous treatment of chronic total occlusions. Catheter Cardiovasc Interv 2017;89:820-8. 
A

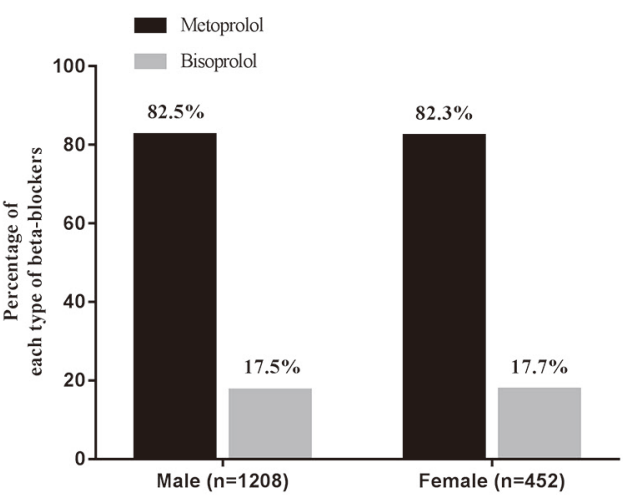

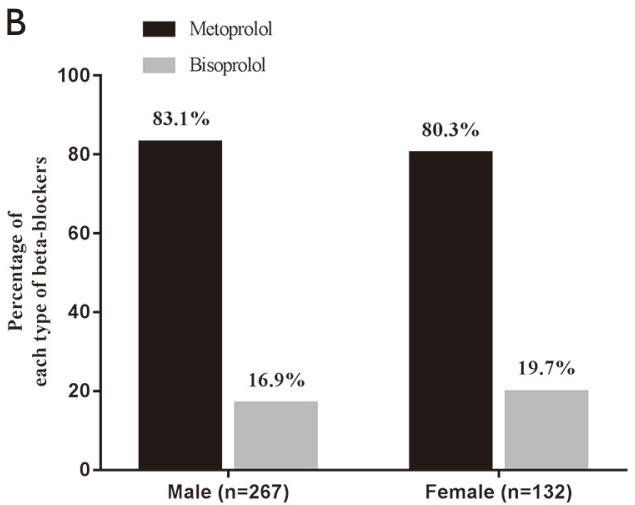

Figure S1 The percentage of each type of $\beta$-blockers used by the patients of prior $\beta$-blocker therapy groups in four groups. (A) In the subgroup of patients below 75 years old, $82.5 \%$ male patients used metoprolol $v s .17 .5 \%$ used bisoprolol before elective PCI, and $82.3 \%$ male patients used metoprolol vs. 17.7\% used bisoprolol, with almost the same percentage; (B) In the subgroup of patients over 75 years old, 83.1\% male patients used metoprolol vs. $16.9 \%$ used bisoprolol before elective PCI, and $80.3 \%$ male patients used metoprolol vs. 19.7\% used bisoprolol, with no significant difference.

Table S1 Baseline characteristics of all patients grouped by the age of 75 years old and gender

\begin{tabular}{|c|c|c|c|c|}
\hline & \multicolumn{2}{|c|}{$<75$ years } & \multicolumn{2}{|c|}{$\geq 75$ years } \\
\hline Age (years) & $61.12 \pm 8.77$ & $64.13 \pm 6.77$ & $79.39 \pm 3.28$ & $79.45 \pm 3.26$ \\
\hline $\mathrm{SBP}(\mathrm{mmHg})$ & $129.01 \pm 18.3$ & $136.41 \pm 18.51$ & $135.84 \pm 20.2$ & $141.61 \pm 21.68$ \\
\hline $\mathrm{DBP}(\mathrm{mmHg})$ & $73.94 \pm 11.98$ & $75.1 \pm 11.87$ & $69.86 \pm 12.38$ & $72.13 \pm 12.3$ \\
\hline Diabetes mellitus (\%) & $581(24.9 \%)$ & $259(30.1 \%)$ & $144(24.9 \%)$ & $76(29.8 \%)$ \\
\hline Heart rate (bpm) & $72.9 \pm 11.52$ & $75.06 \pm 12.01$ & $71.05 \pm 11.7$ & $75.5 \pm 12.49$ \\
\hline Prior $\beta$-blockers (\%) & $1208(51.8 \%)$ & $452(52.5 \%)$ & $267(46.1 \%)$ & $132(51.8 \%)$ \\
\hline Previous MI (\%) & $215(9.2 \%)$ & $27(3.1 \%)$ & $56(9.7 \%)$ & $19(7.5 \%)$ \\
\hline Stable angina (\%) & $1080(46.3 \%)$ & $416(48.3 \%)$ & $267(46.1 \%)$ & $127(49.8 \%)$ \\
\hline ACS (\%) & $976(41.9 \%)$ & $366(42.5 \%)$ & $220(38.0 \%)$ & $101(39.6 \%)$ \\
\hline Asymptomatic myocardial ischemia (\%) & $236(10.1 \%)$ & $68(7.9 \%)$ & $80(13.8 \%)$ & $20(7.8 \%)$ \\
\hline Cerebrovascular disease (\%) & $169(7.2 \%)$ & $67(7.8 \%)$ & $76(13.1 \%)$ & $28(11 \%)$ \\
\hline Family history of CHD (\%) & $238(10.2 \%)$ & $81(9.4 \%)$ & $22(3.8 \%)$ & $13(5.1 \%)$ \\
\hline $\mathrm{BMI}\left(\mathrm{kg} / \mathrm{m}^{2}\right)$ & $25.14 \pm 3.11$ & $24.52 \pm 3.33$ & $23.8 \pm 3$ & $23.98 \pm 3.59$ \\
\hline Current Smoking (\%) & $783(33.6 \%)$ & $10(1.2 \%)$ & 107 (18.5\%) & $6(2.4 \%)$ \\
\hline
\end{tabular}

Table S1 (continued) 
Table S1 (continued)

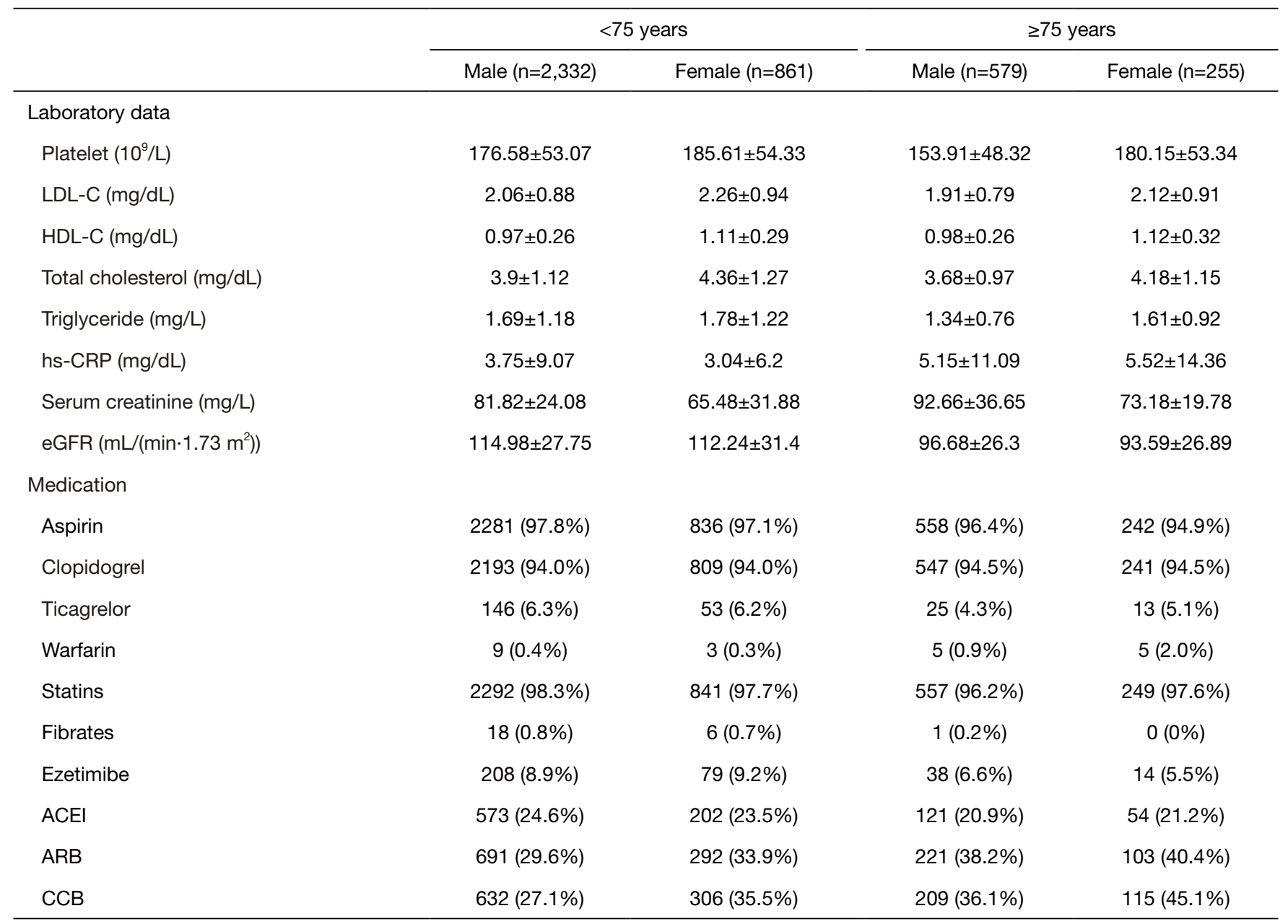

Data are presented as mean \pm SD or $\mathrm{n}(\%)$. The $\mathrm{P}$ values for continuous data were obtained from the analysis of the unpaired $t$-test, the $\mathrm{P}$ values for categorical data were obtained from the chi-square test. SBP, systolic blood pressure; DBP, diastolic blood pressure; MI, myocardial infarction; $\mathrm{PCl}$, percutaneous coronary intervention; CABG, coronary artery bypass grafting; ACS, acute coronary syndrome; CHD, coronary heart disease; BMI, body mass index; LDL-C, low-density lipoprotein-cholesterol; HDL-C, high-density lipoprotein-cholesterol; hs-CRP, high-sensitivity $C$ reactive protein; eGFR, estimated glomerular filtration rate; ACEl, angiotensin-converting enzyme inhibitor; ARB, angiotensin II receptor blockage; CCB, calcium channel blocker. 
Table S2 Angiographic \& procedural characteristics of all patients grouped by the age of 75 years old and gender

\begin{tabular}{|c|c|c|c|c|}
\hline & \multicolumn{2}{|c|}{$<75$ years } & \multicolumn{2}{|c|}{$\geq 75$ years } \\
\hline \multicolumn{5}{|l|}{ Lesion location } \\
\hline Left main & $195(8.4 \%)$ & $60(7 \%)$ & 57 (9.8\%) & $21(8.2 \%)$ \\
\hline Left anterior descending & $1273(54.6 \%)$ & $498(57.8 \%)$ & $294(50.8 \%)$ & $139(54.5 \%)$ \\
\hline Right coronary artery & $682(29.2 \%)$ & $232(26.9 \%)$ & 177 (30.6\%) & $74(29 \%)$ \\
\hline Multivessel intervention & $1.19 \pm 0.47$ & $1.16 \pm 0.44$ & $1.17 \pm 0.48$ & $1.16 \pm 0.45$ \\
\hline 2 vessels & $309(13.3 \%)$ & $100(11.6 \%)$ & $63(10.9 \%)$ & $30(11.8 \%)$ \\
\hline 3 vessels & $63(2.7 \%)$ & $20(2.3 \%)$ & $20(3.5 \%)$ & $6(2.4 \%)$ \\
\hline Moderate or severe calcfication & $407(17.5 \%)$ & $142(16.5 \%)$ & 127 (21.9\%) & $50(19.6 \%)$ \\
\hline Bifurcation lesion & $268(11.5 \%)$ & $76(8.8 \%)$ & $65(11.2 \%)$ & $30(11.8 \%)$ \\
\hline Eccentric lesion & $1337(57.3 \%)$ & $511(59.3 \%)$ & $354(61.1 \%)$ & $142(55.7 \%)$ \\
\hline CTO lesion & $192(8.2 \%)$ & $41(4.8 \%)$ & $45(7.8 \%)$ & $15(5.9 \%)$ \\
\hline Angulated lesions & $127(5.4 \%)$ & $40(4.6 \%)$ & $38(6.6 \%)$ & $9(3.5 \%)$ \\
\hline Thrombus at baseline & $28(2.4 \%)$ & $7(0.8 \%)$ & $3(0.5 \%)$ & $1(0.4 \%)$ \\
\hline Pre-procedural TIMI flow $<3$ & $692(29.7 \%)$ & $226(26.2 \%)$ & $182(31.4 \%)$ & $72(28.2 \%)$ \\
\hline Post-procedural TIMI flow < 3 & $28(1.2 \%)$ & $2(0.2 \%)$ & $9(1.6 \%)$ & $3(1.2 \%)$ \\
\hline Implanted stents $\geq 2$ & $1048(44.9 \%)$ & $390(45.3 \%)$ & $235(40.6 \%)$ & $123(48.2 \%)$ \\
\hline Mean stent length (mm) & $25.39 \pm 6.99$ & $24.63 \pm 6.8$ & $24.79 \pm 6.8$ & $24.66 \pm 6.55$ \\
\hline Total length of implanted stents (mm) & $42.38 \pm 24.56$ & $40.54 \pm 23.18$ & $40.28 \pm 23.9$ & $41.34 \pm 22.17$ \\
\hline FFR IVUS OCT & $335(14.4 \%)$ & $128(14.9 \%)$ & $79(13.6 \%)$ & $36(14.1 \%)$ \\
\hline Predilatation (\%) & $1826(78.3 \%)$ & $687(79.8 \%)$ & $460(79.4 \%)$ & $207(81.2 \%)$ \\
\hline Postdilatation (\%) & $2024(86.8 \%)$ & $768(89.2 \%)$ & $504(87.0 \%)$ & $223(87.5 \%)$ \\
\hline Direct stent (\%) & $374(16.0 \%)$ & $139(16.1 \%)$ & $86(14.9 \%)$ & $36(14.1 \%)$ \\
\hline Rotational atherectomy (\%) & $15(0.6 \%)$ & $5(0.6 \%)$ & $10(1.7 \%)$ & $8(3.1 \%)$ \\
\hline
\end{tabular}

ACC/AHA, American College of Cardiology/American Heart Association; CTO, chronic total occlusions; TIMI, thrombolysis in myocardial infarction; FFR, fractional flow reserve; IVUS, intravenous ultrasound; OCT, optical coherence tomography. 
Table S3 Logistic regression analysis for predictors of PMI in the patients < 75 years old using metoprolol

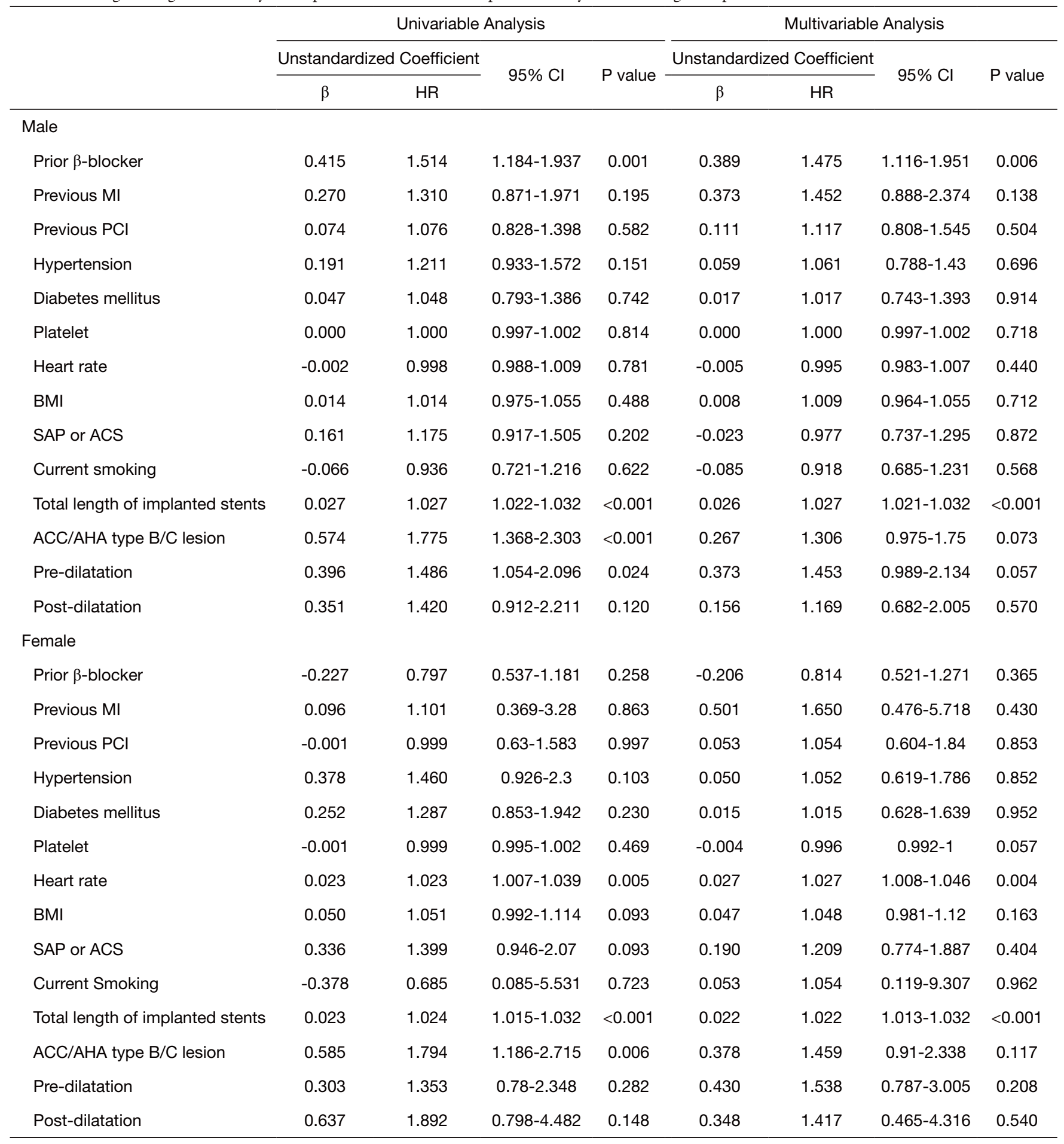

HR: hazard ratio; MI: myocardial infarction; PCl: percutaneous coronary intervention; BMI: body mass index; SAP: stable angina pectoris; ACS: acute coronary syndrome; ACC/AHA: American College of Cardiology/American Heart Association. 
Table S4 Logistic regression analysis for predictors of PMI in the patients $\geq 75$ years old using metoprolol

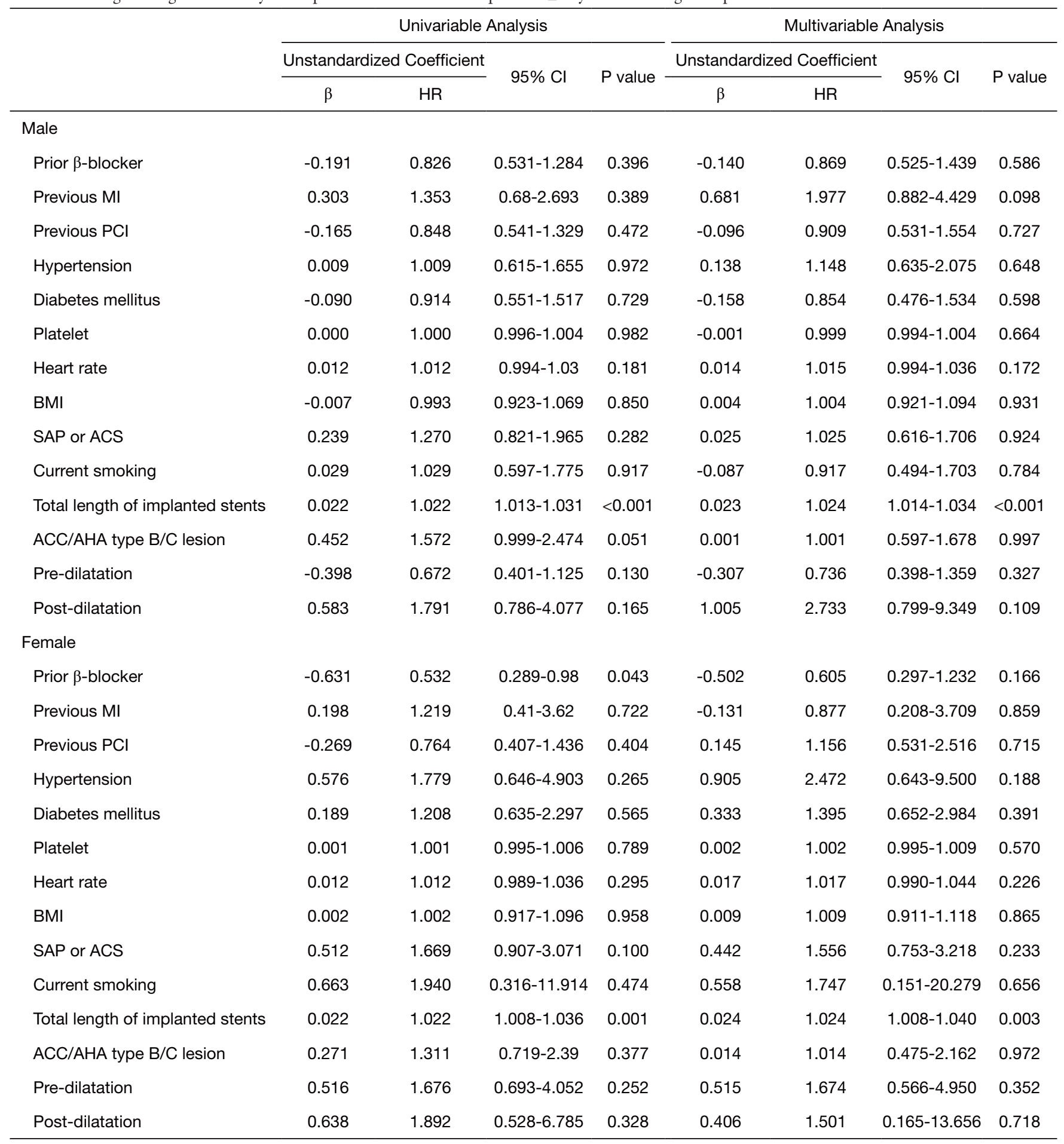

HR: hazard ratio; MI: myocardial infarction; PCl: percutaneous coronary intervention; BMI: body mass index; SAP: stable angina pectoris; ACS: acute coronary syndrome; ACC/AHA: American College of Cardiology/American Heart Association. 